\title{
Genetic variants in the KIF6 region and coronary event reduction from statin therapy
}

\author{
Yonghong Li • Marc S. Sabatine • Carmen H. Tong • Ian Ford • Todd G. Kirchgessner • \\ Christopher J. Packard • Michele Robertson · Charles M. Rowland · Lance A. Bare • \\ James Shepherd · James J. Devlin · Olga A. Iakoubova
}

Received: 8 July 2010 / Accepted: 16 September 2010 / Published online: 1 October 2010

(C) The Author(s) 2010. This article is published with open access at Springerlink.com

\begin{abstract}
A single nucleotide polymorphism (SNP) in KIF6, a member of the KIF9 family of kinesins, is associated with differential coronary event reduction from statin therapy in four randomized controlled trials; this SNP (rs20455) is also associated with the risk for coronary heart disease (CHD) in multiple prospective studies. We investigated whether other common SNPs in the KIF6 region were associated with event reduction from statin therapy. Of the 170 SNPs in the KIF6 region investigated in the Cholesterol and Recurrent Events trial (CARE), 28 were associated with differential event reduction from statin therapy $\left(P_{\text {interaction }}<0.1\right.$ in Caucasians, adjusted for age and sex $)$ and were further investigated in the Pravastatin or Atorvastatin Evaluation and Infection Therapy-Thrombolysis In Myocardial Infarction 22 (PROVE IT-TIMI22) and West of Scotland Coronary Prevention Study (WOSCOPS).
\end{abstract}

Electronic supplementary material The online version of this article (doi:10.1007/s00439-010-0892-6) contains supplementary material, which is available to authorized users.

Y. Li $(\bowtie) \cdot$ C. H. Tong · C. M. Rowland · L. A. Bare .

J. J. Devlin · O. A. Iakoubova

Celera, Alameda, CA 94502, USA

e-mail: yonghong.li@ celera.com

M. S. Sabatine

Brigham \& Women's Hospital,

Harvard Medical School, Boston, MA 02115, USA

I. Ford · C. J. Packard · M. Robertson · J. Shepherd

University of Glasgow and Royal Infirmary,

Glasgow, Scotland, UK

T. G. Kirchgessner

Pharmaceutical Research Institute,

Bristol-Myers Squibb, Princeton, NJ 08543, USA
These analyses revealed that two SNPs (rs9462535 and rs9471077), in addition to rs20455, were associated with event reduction from statin therapy $\left(P_{\text {interaction }}<0.1\right.$ in each of the three studies). The relative risk reduction ranged from 37 to $50 \%(P<0.01)$ in carriers of the minor alleles of these SNPs and from -4 to $13 \%(P>0.4)$ in non-carriers. These three SNPs are in high linkage disequilibrium with one another $\left(r^{2}>0.84\right)$. Functional studies of these variants may help to understand the role of KIF6 in the pathogenesis of CHD and differential response to statin therapy.

\section{Introduction}

The risk for coronary heart disease (CHD) varies between individuals and can be ameliorated by lifestyle changes and medications such as statins. Although statins have been shown to be highly effective in reducing CHD events in randomized controlled trials, individual response to statin therapy varies (reviewed in Mangravite et al. 2006; Schmitz and Langmann 2006), a variability thought to be partly due to genetic factors.

Recently, a common single nucleotide polymorphism (SNP) in KIF6, a member of the KIF9 family of kinesins, has been reported to be associated with CHD risk and differential reduction of coronary events from statin therapy (Bare et al. 2007; Iakoubova et al. 2008a, b, 2009; Shiffman et al. 2008a, b); this SNP (rs20455) encodes the missense polymorphism KIF6 Trp719Arg. In a meta-analysis of seven prospective studies, carriers of the 719Arg variant had over $20 \%$ increased risk of CHD, compared with noncarriers $\left(P=1.02 \times 10^{-6}\right)(\mathrm{Li}$ et al. 2010). This increased risk was independent of traditional risk factors including age, blood pressure, diabetes, smoking, low-density lipoprotein cholesterol (LDL-C) or high-density lipoprotein 
cholesterol (HDL-C). However, an association between the KIF6 Trp719Arg polymorphism and CHD was not observed in two case-control studies (Stewart et al. 2009; Wellcome Trust Case Control Consortium 2007), possibly due to statin use.

The 719Arg variant was also associated with greater reduction of coronary events from both pravastatin (a hydrophilic statin) and atorvastatin (a lipophilic statin) therapy. In retrospective genetic analyses of four prospective clinical trials, the Cholesterol and Recurrent Events trial (CARE) (Sacks et al. 1996), the West of Scotland Coronary Prevention Study (WOSCOPS) (Shepherd et al. 1995), Pravastatin or Atorvastatin Evaluation and Infection Therapy-Thrombolysis In Myocardial Infarction 22 (PROVE IT-TIMI22) (Cannon et al. 2004), and the PROspective Study of Pravastatin in the Elderly at Risk (PROSPER), carriers of the 719Arg variant ( $\sim 60 \%$ of people of European ancestry) had substantial and significant reduction of CHD events from statin therapy, whereas non-carriers did not (Iakoubova et al. 2008a, b, 2009).

Here we have conducted a fine mapping study to determine (1) whether other SNPs or haplotypes in the KIF6 region account for the association of rs20455 (Trp719Arg) with differential coronary event reduction from statin therapy and (2) whether other variants in the KIF6 region are independently associated with differential reduction of events from statin therapy.

\section{Methods}

\section{Study population}

The populations in this genetic study were derived from three prospective double blind, randomized clinical trials that evaluated the effect of statin therapy on coronary events: CARE, PROVE IT-TIMI22, and WOSCOPS. CARE evaluated the effect of $40 \mathrm{mg} /$ day pravastatin, compared with placebo, on the reduction of fatal CHD and nonfatal myocardial infarction (MI) in men and women with a prior MI and LDL-C levels between 115 and $174 \mathrm{mg} / \mathrm{dL}$ (average age of 59 years old); WOSCOPS evaluated the effect of $40 \mathrm{mg} /$ day pravastatin, compared with placebo, on the reduction of fatal and nonfatal CHD in men with LDL-C levels between 174 and $232 \mathrm{mg} / \mathrm{dL}$ (age ranged from 45 to 64 years old) and no history of MI; PROVE IT-TIMI 22 evaluated the effect of intensive statin therapy $(80 \mathrm{mg} /$ day atorvastatin), compared with moderate statin therapy $(40 \mathrm{mg} /$ day pravastatin), on fatal and nonfatal cardiovascular events in men and women after acute coronary syndromes (average age of 58 years old). The average follow-up period was 5, 2 and 4.9 years for the CARE,
PROVE IT-TIMI 22 and WOSCOPS trials, respectively. The current genetic analyses were performed in those patients whose DNA was available: 2,913 in CARE, 1,817 in PROVE IT-TIMI22, and 1,570 in WOSCOPS; note that for WOSCOPS we obtained access to a previously described nested case-control study that included all cases, who had CHD events and age- and smoking status-matched controls who did not have events during the WOSCOPS trial (Packard et al. 2000). This study was limited to Caucasian patients to avoid complications arising from potential differences in linkage disequilibrium (LD) structure in different populations and because each trial enrolled only about $10 \%$ or fewer non-Caucasian patients. Characteristics of the patients included in this genetic study can be found in Supplementary Table 1 .

The endpoints were either the primary endpoint of the original clinical trials (for CARE and PROVE ITTIMI22) or that of the previously reported nested casecontrol study of WOSCOPS (Packard et al. 2000). For CARE, the endpoint was fatal coronary event or nonfatal MI (Shiffman et al. 2010); for PROVE IT-TIMI22, the endpoint was death from any cause or major cardiovascular events including MI, revascularization, unstable angina requiring hospitalization and stroke (Cannon et al. 2004); and for WOSCOPS, the endpoint was CHD death, nonfatal MI, and revascularization (Shepherd et al. 1995). Genotypes were determined in a core facility by either allele-specific real-time PCR (Germer et al. 2000) or multiplexed PCR of genomic DNA followed by multiplexed allele detection (Iannone et al. 2000). Genotyping was carried out in plates with randomly arrayed samples, and genotype calls were made without the knowledge of the sample event status.

\section{SNP selection}

The interrogated region on chromosome 6 spanned from $39,392,028$ to $39,809,728 \mathrm{bp}$, corresponding to the positions of rs 1535500 and rs215497. This region includes the entire KIF6 gene plus $8.6 \mathrm{kbp}$ upstream and $18.8 \mathrm{kbp}$ downstream of the KIF6 gene (Fig. 1). A total of 178 SNPs in this KIF6 region were genotyped in CARE, including rs20455 and 26 other SNPs whose association with risk of CHD had been investigated previously (Iakoubova et al. 2008b). Of the 178 SNPs included in this study, the genotype distributions of five SNPs did not meet Hardy-Weinberg expectations $(P<0.001)$ and three SNPs had an allele frequency less than $2 \%$; the remaining 170 SNPs were analyzed for association with differential coronary event reduction from statin therapy. All 450 SNPs in the KIF6 region in the HapMap dataset (de Bakker et al. 2005) with an allele frequency greater than $2 \%$ were either included in 

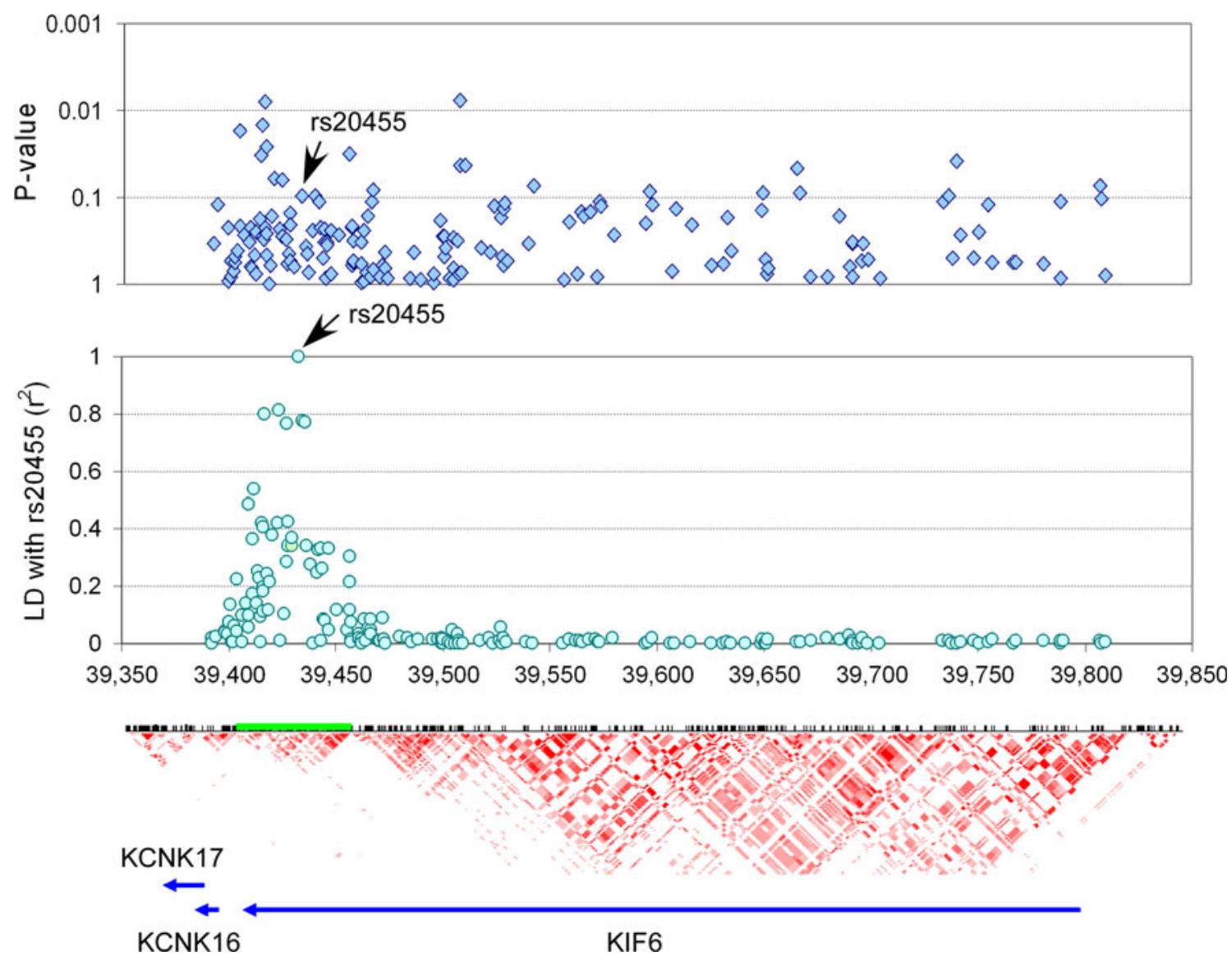

Fig. 1 Linkage disequilibrium and association with statin therapy in CARE. Gene and SNP locations and SNP to SNP LD in the HapMap dataset (in $\mathrm{D}^{\prime}$ ranging from 1 in red to 0 in white) in the KIF6 region are shown in the lower part of the figure. The LD block containing rs20455 is indicated with a green bar. LD between rs20455 and other

these 170 SNPs or in LD $\left(r^{2}>0.8\right)$ with one of the 170 SNPs.

One objective of the current study was to determine the presence of a SNP in the KIF6 region that could explain the association of KIF6 Trp719Arg SNP with differential reduction of coronary events from statin. Therefore, to avoid missing such a hypothetical 'causative' SNP that, by chance, had a weak association in one of the studies we set a relaxed threshold $\left(P_{\text {interaction }}<0.1\right)$ for advancing SNPs from one study to the next. Therefore, the flow of the study was as following: SNPs were first tested in CARE, and those that were associated with differential reduction of events from statin therapy $\left(P_{\text {interaction }}<0.1\right)$ were then analyzed in PROVE ITTIMI22. SNPs that were associated with statin response in PROVE IT-TIMI22 $\left(P_{\text {interaction }}<0.1\right.$ and hazard ratio in the same direction as in CARE) were further analyzed in WOSCOPS. We adopted this sequence of analysis partly because only a limited amount of DNA was available from patients in the WOSCOPS study. genotyped SNPs in CARE is shown in the middle part of the figure. Nucleotide position on the chromosome is indicated below the $x$ axis in kilobases. Association between SNP and event reduction in CARE (dominant model $P_{\text {interaction }}$ ) is presented in the top panel

Statistical analyses

Genotype distribution in the individual studies was tested for deviation from Hardy-Weinberg equilibrium (HWE) by an exact test.

For each SNP, likelihood ratio tests comparing Cox (CARE and PROVE IT-TIMI22) or logistic regression models (WOSCOPS) with and without an interaction term between genotype and statin therapy were used to evaluate heterogeneity (measured by $P_{\text {interaction}}$ ) of event reduction from statin therapy. Additive, dominant, and recessive models for each SNP were coded using the major allele (defined in CARE) as the reference allele so that the direction of estimated parameters would be consistently measured across all three studies.

The LD measure $r^{2}$ was calculated from unphased data with the LDMAX program in the GOLD package (Abecasis and Cookson 2000). Haplotype frequencies were estimated from the genotype data and, using the posterior probabilities of possible haplotype pairs for each subject, 
tested for association with heterogeneity of event reduction from statin therapy using logistic regression as implemented in the R package haplo.stats (Lake et al. 2003; Schaid et al. 2002). A sliding window was used to select haplotypes consisting of three or five adjacent SNPs.

\section{Results}

To fine map the KIF6 region, we analyzed 170 SNPs to determine whether reduction of fatal CHD or confirmed nonfatal MI events from statin therapy in CARE differed between genotype-defined subgroups as assessed by the interaction between genotype and treatment group ( $P_{\text {interaction }}$, see "Methods"). We found that 44 SNPs met the $P_{\text {interaction }}$ threshold of $<0.1$ (Supplementary Tables 2, 3 and 4). Of the 17 SNPs associated with differential reduction of events from statin therapy in the recessive model, 16 SNPs were excluded from further analysis, because for each of these SNPs, fewer than $4 \%$ of the patients were minor homozygotes and there were very few events $(<10)$ among the minor homozygotes. The remaining 28 SNPs (including rs20455) associated with differential reduction of events from statin therapy included 12 SNPs that were in LD with rs20455 and clustered in a $53 \mathrm{kbp}$ region (Fig. 1, indicated by a green bar above the LD map).

We then analyzed these 28 SNPs in the PROVE ITTIMI22 cohort using the genetic model for each SNP that was most significant in the CARE analysis. Six SNPs were associated with differential event reduction from statin therapy $\left(P_{\text {interaction }}<0.1\right)$ in PROVE IT-TIMI22, and event reduction from statin therapy was greatest in the same genotype for all six SNPs: 2 in the additive model and 4 in the dominant model (Supplementary Tables 5 and 6). Further analyses of these six SNPs in the WOSCOPS study showed that three SNPs (rs20455, rs9462535 and rs9471077) were differentially associated with coronary event reduction by statin use $\left(P_{\text {interaction }}<0.1\right.$, dominant model; Table 1; Fig. 2). These three SNPs were in high LD with each other $\left(r^{2}=0.84-0.98\right)$ (Supplementary Table 7).

We next carried out haplotype analyses in CARE in the $53 \mathrm{kbp}$ region of high LD surrounding rs20455 (green bar in Fig. 1) using a sliding window approach (Schaid et al. 2002). Results of haplotypes comprising three SNPs along with the results of the most significant individual SNP in a given haplotype are shown in Supplemental Fig. 1. In CARE, only the haplotypes based on rs45460596, rs9394585 and rs9357303 were more significantly associated with event reduction than the best of the three SNPs

Table 1 Association of the three SNPs in the KIF6 region with differential reduction of coronary events from statin therapy in CARE, PROVE IT-TIMI 22 and WOSCOPS studies

\begin{tabular}{|c|c|c|c|c|c|c|c|c|c|c|c|c|}
\hline \multirow[t]{2}{*}{ SNP type } & \multirow[t]{2}{*}{ Study } & \multirow[t]{2}{*}{ Genotype } & \multicolumn{2}{|l|}{ Drug* } & \multicolumn{2}{|c|}{ Comparator* } & \multicolumn{3}{|l|}{ Model $1 * *$} & \multicolumn{3}{|l|}{ Model 2*** } \\
\hline & & & Events & Total & Events & Total & HR or OR $(95 \% \mathrm{CI})$ & $P_{\text {response }}$ & $P_{\text {interaction }}$ & HR or OR $(95 \% \mathrm{CI})$ & $P_{\text {response }}$ & $P_{\text {interaction }}$ \\
\hline \multirow{6}{*}{$\begin{array}{l}\text { rs20455 } \\
\text { Trp719Arg }\end{array}$} & \multirow{2}{*}{ CARE } & $\mathrm{CT}+\mathrm{CC}$ & 76 & 810 & 111 & 791 & $0.65(0.49-0.88)$ & 0.0045 & \multirow[t]{2}{*}{0.0975} & $0.67(0.50-0.90)$ & 0.0074 & \multirow[t]{2}{*}{0.1708} \\
\hline & & $\mathrm{TT}$ & 52 & 554 & 51 & 542 & $0.98(0.67-1.45)$ & 0.9241 & & $0.93(0.63-1.38)$ & 0.6749 & \\
\hline & \multirow[t]{2}{*}{ PROVE IT-TIMI22 } & $\mathrm{CT}+\mathrm{CC}$ & 90 & 533 & 142 & 532 & $0.60(0.46-0.78)$ & 0.0001 & \multirow{2}{*}{0.0206} & $0.62(0.48-0.80)$ & 0.0003 & \multirow{2}{*}{0.0292} \\
\hline & & $\mathrm{TT}$ & 87 & 375 & 91 & 375 & $0.94(0.70-1.26)$ & 0.6802 & & $0.96(0.70-1.32)$ & 0.8226 & \\
\hline & \multirow[t]{2}{*}{ WOSCOPS } & $\mathrm{CT}+\mathrm{CC}$ & 108 & 330 & 172 & 263 & $0.50(0.37-0.67)$ & $<0.0001$ & \multirow{2}{*}{0.0063} & $0.50(0.37-0.68)$ & $<0.0001$ & \multirow{2}{*}{0.0116} \\
\hline & & $\mathrm{TT}$ & 81 & 213 & 104 & 256 & $0.94(0.66-1.32)$ & 0.7055 & & $0.89(0.63-1.26)$ & 0.5126 & \\
\hline \multirow{6}{*}{$\begin{array}{l}\text { rs9462535 } \\
\text { Intronic }\end{array}$} & \multirow[t]{2}{*}{ CARE } & $\mathrm{AC}+\mathrm{AA}$ & 78 & 873 & 110 & 832 & $0.66(0.50-0.89)$ & 0.0056 & \multirow{2}{*}{0.0634} & $0.67(0.50-0.90)$ & 0.0084 & \multirow[t]{2}{*}{0.1171} \\
\hline & & $\mathrm{CC}$ & 55 & 535 & 53 & 538 & $1.04(0.71-1.52)$ & 0.8333 & & $0.99(0.67-1.44)$ & 0.9383 & \\
\hline & \multirow[t]{2}{*}{ PROVE IT-TIMI22 } & $\mathrm{AC}+\mathrm{AA}$ & 97 & 568 & 149 & 558 & $0.61(0.47-0.79)$ & 0.0001 & \multirow{2}{*}{0.0258} & $0.61(0.47-0.79)$ & 0.0002 & \multirow[t]{2}{*}{0.0273} \\
\hline & & $\mathrm{CC}$ & 80 & 340 & 85 & 349 & $0.95(0.70-1.30)$ & 0.7603 & & $0.95(0.69-1.29)$ & 0.7327 & \\
\hline & \multirow[t]{2}{*}{ WOSCOPS } & $\mathrm{AC}+\mathrm{CC}$ & 113 & 335 & 184 & 279 & $0.51(0.39-0.68)$ & $<0.0001$ & \multirow{2}{*}{0.0144} & $0.51(0.38-0.68)$ & $<0.0001$ & \multirow{2}{*}{0.0188} \\
\hline & & $\mathrm{CC}$ & 75 & 197 & 96 & 228 & $0.90(0.63-1.29)$ & 0.5805 & & $0.87(0.60-1.25)$ & 0.4538 & \\
\hline \multirow{6}{*}{$\begin{array}{l}\text { rs9471077 } \\
\text { Intronic }\end{array}$} & \multirow[t]{2}{*}{ CARE } & $\mathrm{CT}+\mathrm{CC}$ & 70 & 813 & 106 & 789 & $0.63(0.47-0.85)$ & 0.0026 & \multirow[t]{2}{*}{0.0258} & $0.64(0.47-0.87)$ & 0.0042 & \multirow[t]{2}{*}{0.0517} \\
\hline & & $\mathrm{TT}$ & 52 & 488 & 47 & 488 & $1.10(0.74-1.64)$ & 0.6309 & & $1.04(0.70-1.55)$ & 0.8401 & \\
\hline & \multirow[t]{2}{*}{ PROVE IT-TIMI22 } & $\mathrm{CT}+\mathrm{CC}$ & 99 & 569 & 149 & 560 & $0.62(0.48-0.80)$ & 0.0002 & \multirow{2}{*}{0.0320} & $0.59(0.45-0.77)$ & 0.0001 & 0.0816 \\
\hline & & $\mathrm{TT}$ & 78 & 335 & 83 & 344 & $0.96(0.70-1.31)$ & 0.7984 & & $0.94(0.70-1.28)$ & 0.7081 & \\
\hline & WOSCOPS & $\mathrm{CT}+\mathrm{CC}$ & 113 & 340 & 175 & 284 & $0.54(0.41-0.72)$ & $<0.0001$ & 0.0146 & $0.54(0.40-0.72)$ & $<0.0001$ & 0.0178 \\
\hline & & $\mathrm{TT}$ & 76 & 196 & 94 & 231 & $0.95(0.67-1.36)$ & 0.7914 & & $0.92(0.64-1.32)$ & 0.6365 & \\
\hline
\end{tabular}

* Drug was Pravastatin in CARE and WOSCPS and Atorvastatin in PROVE IT-TIMI22; Comparator was placebo in CARE and WOSCOPS and pravastatin in PROVE IT-TIMI22

** Model 1 for CARE and PROVE IT-TIMI22 is adjusted for age and sex; WOSCOPS is unadjusted

*** Model 2 is adjusted for age, smoking, hypertension, diabetes, high-density cholestrol (HDL-C) level, and non-HDL-C level; additional adjustments include sex and body mas index for CARE, sex and treatment for gatifloxacin for PROVE IT-TIMI22 
Fig. 2 Effect of statin therapy on coronary events stratified by the genotype of three SNPs in CARE, PROVE IT-TIMI22 and WOSCOPS studies. The hazard ratios or odds ratios were calculated for Model 2 in Table 1

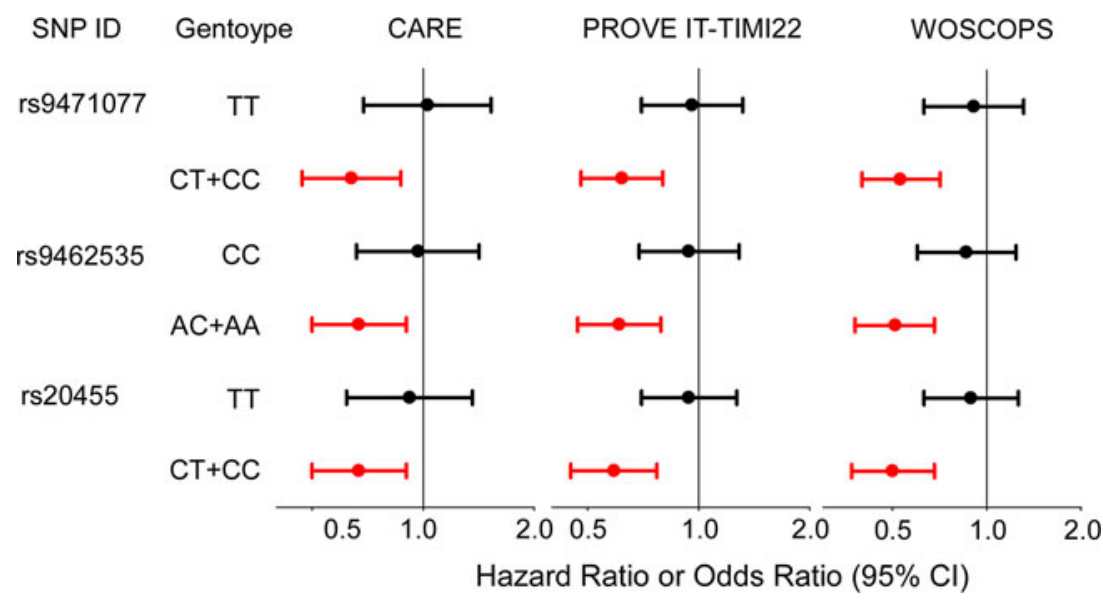

Table 2 Association of the three SNPs in the KIF6 region and coronary events in the placebo groups of CARE and WOSCOPS

\begin{tabular}{|c|c|c|c|c|c|c|}
\hline \multirow[t]{2}{*}{ SNP } & \multirow[t]{2}{*}{ Genotype } & \multirow[t]{2}{*}{ Study } & \multicolumn{2}{|l|}{ Model 1* } & \multicolumn{2}{|l|}{ Model 2** } \\
\hline & & & HR or OR $(95 \% \mathrm{CI})$ & $P$ & HR or OR $(95 \% \mathrm{CI})$ & $P$ \\
\hline \multirow[t]{2}{*}{ rs 20455} & \multirow[t]{2}{*}{$\mathrm{CT}+\mathrm{CC}$ versus $\mathrm{TT}$} & CARE & $1.54(1.10-2.14)$ & 0.0112 & $1.48(1.06-2.06)$ & 0.0215 \\
\hline & & WOSCOPS & $1.61(1.19-2.17)$ & 0.0017 & $1.55(1.15-2.10)$ & 0.0045 \\
\hline \multirow[t]{2}{*}{ rs9462535 } & \multirow[t]{2}{*}{$\mathrm{AC}+\mathrm{AA}$ versus $\mathrm{CC}$} & CARE & $1.38(1.00-1.92)$ & 0.0530 & $1.32(0.95-1.84)$ & 0.0944 \\
\hline & & WOSCOPS & $1.57(1.16-2.12)$ & 0.0036 & $1.53(1.12-2.08)$ & 0.0069 \\
\hline \multirow[t]{2}{*}{ rs9471077 } & \multirow[t]{2}{*}{$\mathrm{CT}+\mathrm{CC}$ versus $\mathrm{TT}$} & CARE & $1.44(1.02-2.03)$ & 0.0376 & $1.38(0.98-1.95)$ & 0.0678 \\
\hline & & WOSCOPS & $1.51(1.12-2.05)$ & 0.0077 & $1.46(1.07-1.99)$ & 0.0160 \\
\hline
\end{tabular}

* Model 1 for CARE is adjusted for age and sex; WOSCOPS is unadjusted

** Model 2 is adjusted for age, smoking, hypertension, diabetes, body mass index, high density cholesterol (HDL-C) level, and non-HDL-C level; CARE is also adjusted for sex

alone (dominant $P_{\text {interaction }}=0.0088$ vs. 0.097 ); however, in PROVE IT-TIMI22 these haplotypes were not associated with event reduction (dominant haplotype $P_{\text {interaction }}=$ 0.55). Testing of haplotypes consisting of five adjacent SNPs did not reveal any haplotype that was more significant than the corresponding individual SNPs (data not shown).

We also carried out a haplotype analysis in CARE of the three SNPs (rs9471077, rs9462535, and rs20455) that were associated with event reduction in all three studies. Two common (>5\%) haplotypes were observed, which corresponded to KIF6 710Arg carriers and non-carriers (data not shown). Due to the high LD between these three SNPs, we were unable to differentiate the effects of one SNP from another despite exploring both pairwise adjustment and stepwise regression analyses. For example, there were only six events each in placebo and statin-treated subjects among the combinations where the genotypes are discordant (data not shown).

Since rs20455 had also been reported to be associated with CHD, we analyzed association of the two other SNPs (rs9462535 and rs9471077) that were consistently associated with event reduction in CARE and WOSCOPS. We found that they were also associated with CHD (Table 2).

\section{Discussion}

This study was designed to investigate whether (1) the previously reported association of rs20455 (Trp719Arg) with coronary event reduction from statin therapy could be better explained by another SNP in the KIF6 region and (2) other SNPs in the KIF6 region were associated with coronary event reduction from statin therapy independently of rs20455. We found that two additional SNPs in strong LD with rs20455 were consistently associated $\left(P_{\text {interaction }}<0.1\right)$ with differential reduction of clinical events from statin therapy in the CARE, WOSCOPS, and PROVE IT-TIMI22 studies. These two SNPs are located in introns, while rs20455 is a missense polymorphism in the KIF6 gene.

Previously, we have tested 27 SNPs, including rs20455, in a $95.5 \mathrm{kbp}$ portion of the KIF6 region (from position $39,347,330$ to position $39,442,863$ on chromosome 6) for association with CHD in the placebo arms of the CARE and WOSCOPS studies (Iakoubova et al. 2008b). This study expands the interrogated region and focuses on differential event reduction from statin therapy, an effect of particular clinical interest. The three SNPs that we found to be associated with differential response to statin therapy are highly correlated and thus indistinguishable from each 
other in this association. However, the possibility that the 719Trp versus 719Arg variation has functional consequences is supported by the BLOSUM62 score of -3 for this variation. The BLOSUM62 score is the log odds for amino acid substitutions in conserved protein blocks (Henikoff and Henikoff 1992), and a score of -3 indicates a less likely substitution. As the Trp719Arg substitution is near the putative cargo-binding tail domain of the kinesin, it would be interesting to determine whether the amino acid change affects the binding of cargo molecules by the KIF6 protein.

One limitation of our study is that we were unable to define the causal variant with certainty. Strategies to identify causal variants include performing genetic association studies in a different population that might have a distinct LD structure for these tightly linked SNPs from the initial studies. The CARE and PROVE IT-TIMI22 cohorts had small numbers of non-Caucasian participants; therefore, the power to conduct an association study in the non-Caucasian population is limited. Another limitation is that PROVE IT-TIMI22 may not be comparable to CARE and WOSCOPS-the former tested intensive statin therapy compared with moderate statin therapy, while the latter tested $40 \mathrm{mg} /$ day pravastatin compared with placebo. Therefore, by including PROVE IT-TIMI22, we may have missed the SNPs that are capable of predicting event reduction response to pravastatin compared with placebo but not intensive statin therapy compared with moderate statin therapy. Such SNPs may be independent from rs20455, which predicts differential event reduction from both $40 \mathrm{mg} /$ day pravastatin compared with placebo and intensive statin therapy compared with moderate statin therapy. In addition, PROVE IT-TIMI22 primary endpoint included a small fraction (5.2\% of primary events) of death from presumably non-cardiovascular events, while the CARE endpoint and the WOSCOPS case definition did not include non-cardiovascular death.

In conclusion, we have identified three highly linked SNPs in the KIF6 region that predict differential reduction of coronary events from statin therapy. Functional characterization of these variants is warranted and could help to explain the role of KIF6 in the pathogenesis of $\mathrm{CHD}$ and the variable event reduction in response to statin therapy.

Acknowledgments We would like to express our gratitude to patients and clinical investigators of the CARE, WOSCOPS and PROVE IT-TIMI22 trials.

Open Access This article is distributed under the terms of the Creative Commons Attribution Noncommercial License which permits any noncommercial use, distribution, and reproduction in any medium, provided the original author(s) and source are credited.

\section{References}

Abecasis GR, Cookson WO (2000) GOLD—graphical overview of linkage disequilibrium. Bioinformatics 16:182-183

Bare LA, Morrison AC, Rowland CM, Shiffman D, Luke MM, Iakoubova OA, Kane JP, Malloy MJ, Ellis SG, Pankow JS, Willerson JT, Devlin JJ, Boerwinkle E (2007) Five common gene variants identify elevated genetic risk for coronary heart disease. Genet Med 9:682-689

Cannon CP, Braunwald E, McCabe CH, Rader DJ, Rouleau JL, Belder R, Joyal SV, Hill KA, Pfeffer MA, Skene AM (2004) Intensive versus moderate lipid lowering with statins after acute coronary syndromes. N Engl J Med 350:1495-1504

de Bakker PI, Yelensky R, Pe'er I, Gabriel SB, Daly MJ, Altshuler D (2005) Efficiency and power in genetic association studies. Nat Genet 37:1217-1223

Germer S, Holland MJ, Higuchi R (2000) High-throughput SNP allelefrequency determination in pooled DNA samples by kinetic PCR. Genome Res 10:258-266

Henikoff S, Henikoff JG (1992) Amino acid substitution matrices from protein blocks. Proc Natl Acad Sci USA 89:10915-10919

Iakoubova OA, Sabatine MS, Rowland CM, Tong CH, Catanese JJ, Ranade K, Simonsen KL, Kirchgessner TG, Cannon CP, Devlin JJ, Braunwald E (2008a) Polymorphism in KIF6 gene and benefit from statins after acute coronary syndromes: results from the PROVE IT-TIMI 22 study. J Am Coll Cardiol 51:449-455

Iakoubova OA, Tong CH, Rowland CM, Kirchgessner TG, Young BA, Arellano AR, Shiffman D, Sabatine MS, Campos H, Packard CJ, Pfeffer MA, White TJ, Braunwald E, Shepherd J, Devlin JJ, Sacks FM (2008b) Association of the Trp719Arg polymorphism in kinesin-like protein 6 with myocardial infarction and coronary heart disease in 2 prospective trials: the CARE and WOSCOPS trials. J Am Coll Cardiol 51:435-443

Iakoubova OA, Robertson M, Tong CH, Rowland CM, Catanese JJ, Blauw GJ, Jukema JW, Murphy MB, Devlin JJ, Ford I, Shepherd J (2009) KIF6 Trp719Arg polymorphism and effect of statin therapy in elderly patients: results from the PROSPER study. Eur J Cardio Prev Rehab 51:455-461

Iannone MA, Taylor JD, Chen J, Li MS, Rivers P, Slentz-Kesler KA, Weiner MP (2000) Multiplexed single nucleotide polymorphism genotyping by oligonucleotide ligation and flow cytometry. Cytometry 39:131-140

Lake SL, Lyon H, Tantisira K, Silverman EK, Weiss ST, Laird NM, Schaid DJ (2003) Estimation and tests of haplotype-environment interaction when linkage phase is ambiguous. Hum Hered 55:56-65

Li Y, Iakoubova O, Shiffman D, Devlin JJ, Forrester JS, Superko HR (2010) KIF6 polymorphism as a predictor of risk of coronary events and of clinical event reduction by statin therapy. Am J Cardiol 106:994-998

Mangravite LM, Thorn CF, Krauss RM (2006) Clinical implications of pharmacogenomics of statin treatment. Pharmacogenomics J 6:360-374

Packard CJ, O’Reilly DS, Caslake MJ, McMahon AD, Ford I, Cooney J, Macphee CH, Suckling KE, Krishna M, Wilkinson FE, Rumley A, Lowe GD (2000) Lipoprotein-associated phospholipase A2 as an independent predictor of coronary heart disease. West of Scotland Coronary Prevention Study Group. N Engl J Med 343:11481155

Sacks FM, Pfeffer MA, Moye LA, Rouleau JL, Rutherford JD, Cole TG, Brown L, Warnica JW, Arnold JM, Wun CC, Davis BR, Braunwald E (1996) The effect of pravastatin on coronary events after myocardial infarction in patients with average cholesterol levels. Cholesterol and Recurrent Events Trial investigators. N Engl J Med 335:1001-1009 
Schaid DJ, Rowland CM, Tines DE, Jacobson RM, Poland GA (2002) Score tests for association between traits and haplotypes when linkage phase is ambiguous. Am J Hum Genet 70:425-434

Schmitz G, Langmann T (2006) Pharmacogenomics of cholesterollowering therapy. Vascul Pharmacol 44:75-89

Shepherd J, Cobbe SM, Ford I, Isles CG, Lorimer AR, MacFarlane PW, McKillop JH, Packard CJ (1995) Prevention of coronary heart disease with pravastatin in men with hypercholesterolemia. West of Scotland Coronary Prevention Study Group. N Engl J Med 333:1301-1307

Shiffman D, Chasman DI, Zee RY, Iakoubova OA, Louie JZ, Devlin JJ, Ridker PM (2008a) A kinesin family member 6 variant is associated with coronary heart disease in the Women's Health Study. J Am Coll Cardiol 51:444-448

Shiffman D, O’Meara ES, Bare LA, Rowland CM, Louie JZ, Arellano AR, Lumley T, Rice K, Iakoubova O, Luke MM, Young BA, Malloy MJ, Kane JP, Ellis SG, Tracy RP, Devlin JJ, Psaty BM (2008b) Association of gene variants with incident myocardial infarction in the Cardiovascular Health Study. Arterioscler Thromb Vasc Biol 28:173-179

Shiffman D, Sabatine MS, Louie JZ, Kirchgessner TG, Iakoubova O, Campos H, Devlin JJ, Sacks F (2010) Effect of pravastatin therapy on coronary events in carriers of the KIF6 719Arg allele from the cholesterol and recurrent events trial. Am J Cardiol 105:1300 1305

Stewart AF, Dandona S, Chen L, Assogba O, Belanger M, Ewart G, LaRose R, Doelle H, Williams K, Wells GA, McPherson R, Roberts R (2009) Kinesin family member 6 variant Trp719Arg does not associate with angiographically defined coronary artery disease in the Ottawa Heart Genomics Study. J Am Coll Cardiol 53:1471-1472

Wellcome Trust Case Control Consortium (2007) Genome-wide association study of 14, 000 cases of seven common diseases and 3, 000 shared controls. Nature 447:661-678 